\title{
GIANT PREPUCIAL PENILE ELEPHANTIASIS OF IDIOPATHIC ETIOLOGY- A CASE REPORT
}

\author{
Charan Panda ${ }^{1}$, Jamaluddin², Nalini Kant Mohanty ${ }^{3}$
}

HOW TO CITE THIS ARTICLE:

Charan Panda, Jamaluddin, Nalini Kant Mohanty. "Giant prepucial penile elephantiasis of idiopathic etiology- a case report". Journal of Evolution of Medical and Dental Sciences 2013; Vol2, Issue 33, August 19; Page: 63286334.

\section{ABSTRACT:}

BACKGROUND: Untreated genital elephantiasis is a common problem amongst India's poor due to lack of access to surgical management. At present medical treatment of elephantiasis is ineffective and even surgical treatment is tedious and often cosmetically unsatisfactory. However, surgical skills required are not always complicated and even experienced general surgeon may offer significant relief with no access to plastic or urological surgeons.

CASE PRESENTATION: The case presented here is that of a very poor middle aged man who had developed grotesque prepucial elephantiasis to the extent of hampering urination (acute urinary retention). He was immensely benefitted by surgery (excision of lesion and split thickness skin graft) with adequate cosmetic and functional outcome.

CONCLUSION: In this case report we discuss a rare case of prepucial elephantiasis, related to poverty and ignorance is amenable to surgery. Surgery provides cosmetically acceptable and functionally adequate outcome.

KEYWORDS: Elephantiasis, Prepeucial, Lymphoedema

INTRODUCTION: Gross genital lymphoedema often due to Filariasis is one of the curse of tropical countries (viz. Africa, India), where it is an endemic entity. The obstruction of lymphatic flow with ductal ectasia leads to hypertrophy and hyperplasia of connective tissue, with interstitial edema, infiltrated by cells characterizing a chronic inflammatory process. ${ }^{1,3}$

The thickening of cutaneous tissue with enlargement of the affected area because of inadequate lymphatic drainage is the main clinical characteristic of lymphoedema. ${ }^{4,6}$

Involvement of external genitalia causing a marked enlargement of its volume and appearance is an uncomfortable clinical scenario with impairment of movement, hygiene, voiding and sexual intercourse. $4,5,7$

The penoscrotal lymphoedema is classified as primary when it is due to lymphatic malformation and secondary when it results from lymphatic obstruction following parasitic and infectious disease, postsurgical and radiation therapy or from other clinical conditions such as, hepatic, cardiac and renal disease. 1,2,3

Regardless of the cause of penoscrotal elephantiasis the disease can lead to physical and spiritual weakness and its treatment is difficult particularly in the aged.

CASE REPORT: A 30 yr old unmarried, farmer, hailing from a remote village in Ganjam district of Odisha, came in contact with authors with complaint of acute urinary retention and swelling of penis. 
He reported the history of insidious, painless, slowly progressive swelling of the distal part of penis for 12 years which had been intensified during the past two years.

No history of trauma, irradiation (therapeutic), surgery or infection was reported.

No history of similar lesion in his relative or his acquaintance at its place of abode.

He is unmarried, not habituated to any form of tobacco and alcohol.

On Examination-
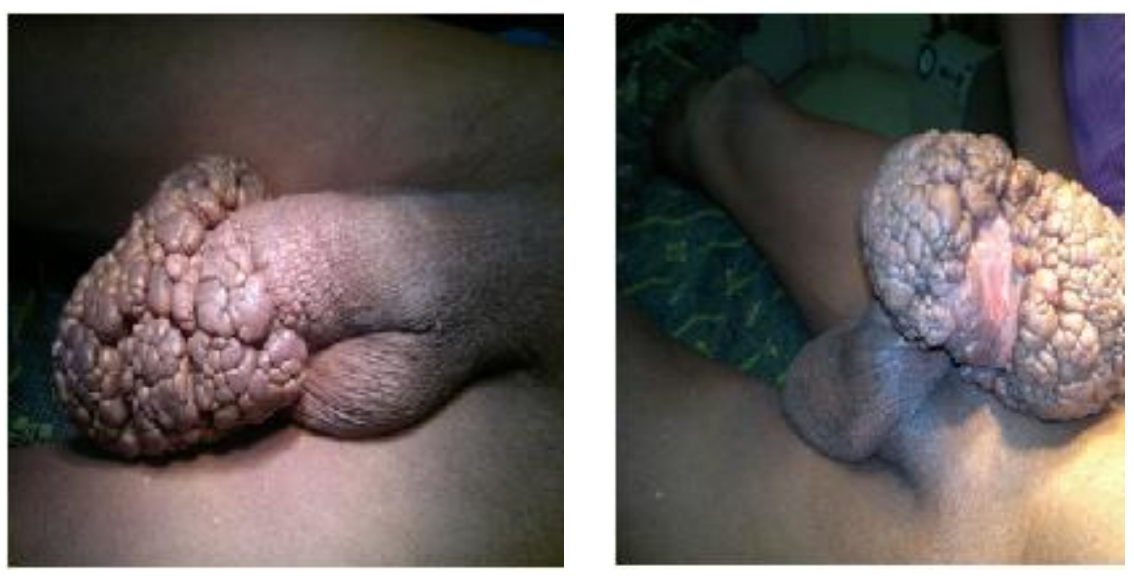

A healthy looking young man with hyperpigmented, non ulcerated, huge, verrucous, solid, soft, nontender, nonpitting mass of size $7 \times 5 \times 4 \mathrm{~cm}$ was appreciated on distal part of penis. Skin overlying the shaft of penis was thickened.

External urethral meatus and glans penis were not visible and difficult to differentiate from the lesion. Scrotum, testicles and spermatic cord appear as normal and inguinal lymph nodes are not enlarged.

Hemogram, Serum electrolyte, urea and creatinine, urine analysis, urine microscopy, culture and sensitivity appears within normal limits.

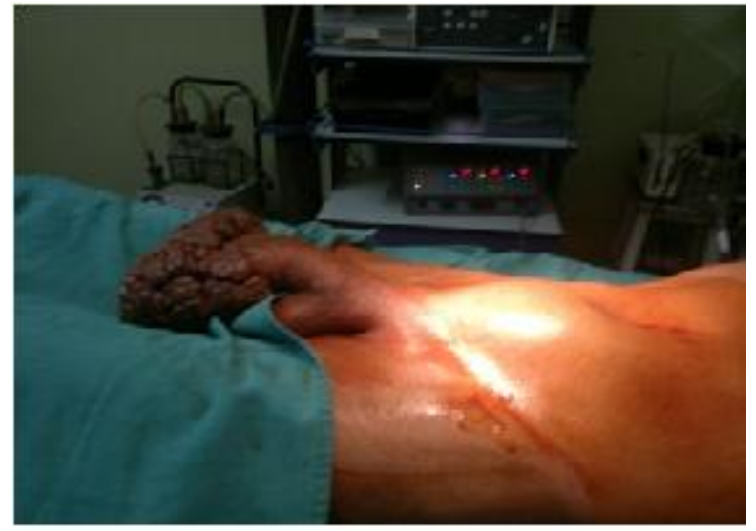

With the diagnosis of idiopathic prepucial elephantiasis, and after presurgical preparation, the patient subsequently underwent excision of lesion in toto. The thickened penile skin was excised immediately above Buck's fascia upto balanoprepucial sulcus. The raw penile shaft was covered with 


\section{CASE REPORT}

a split thickness skin graft harvested from anterior surface of thigh. Stapling was performed on the graft on ventral surface for anchoring.
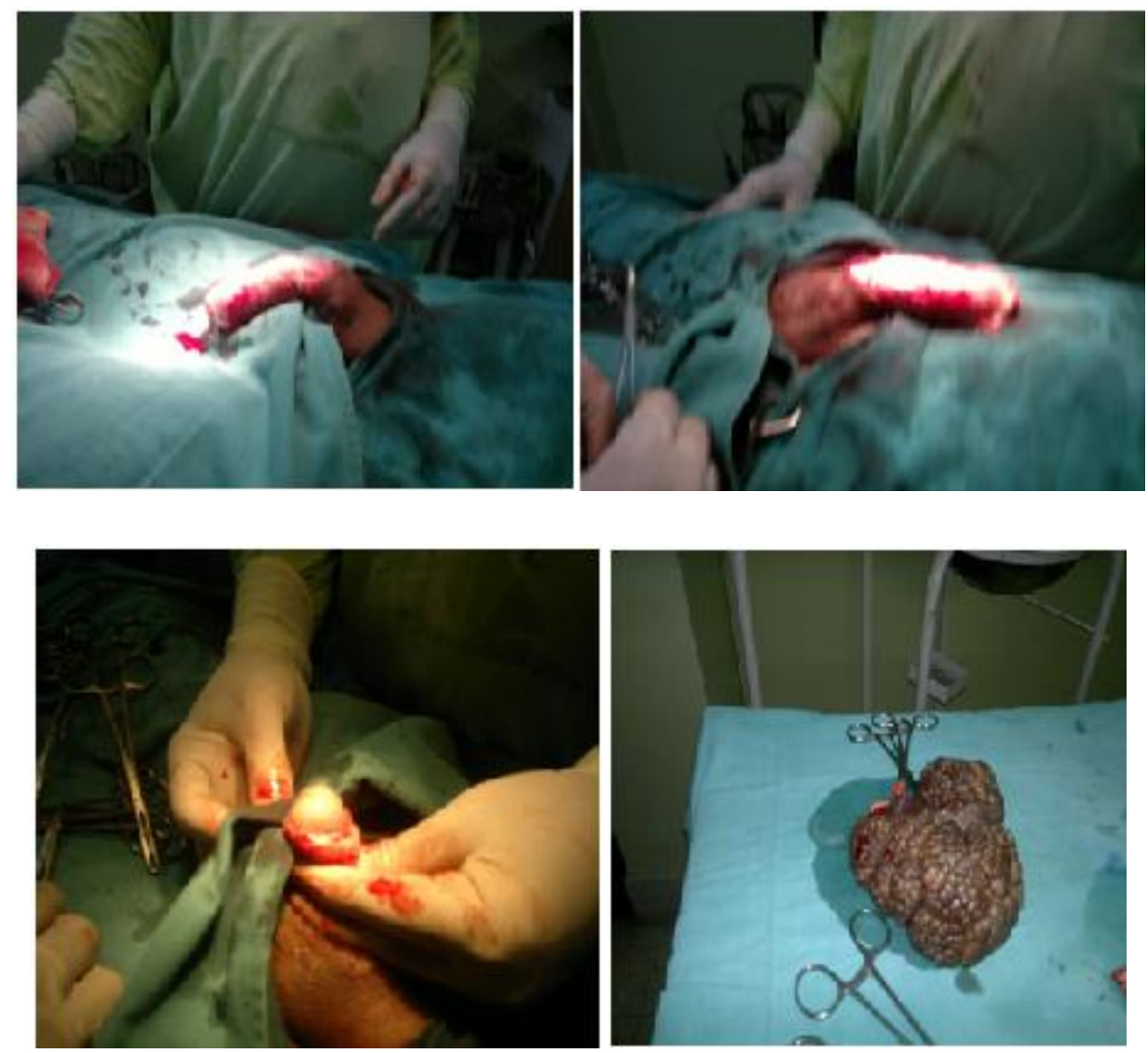

Transoperative images showing penile shaft, after resection of affected prepuce and penile skin.
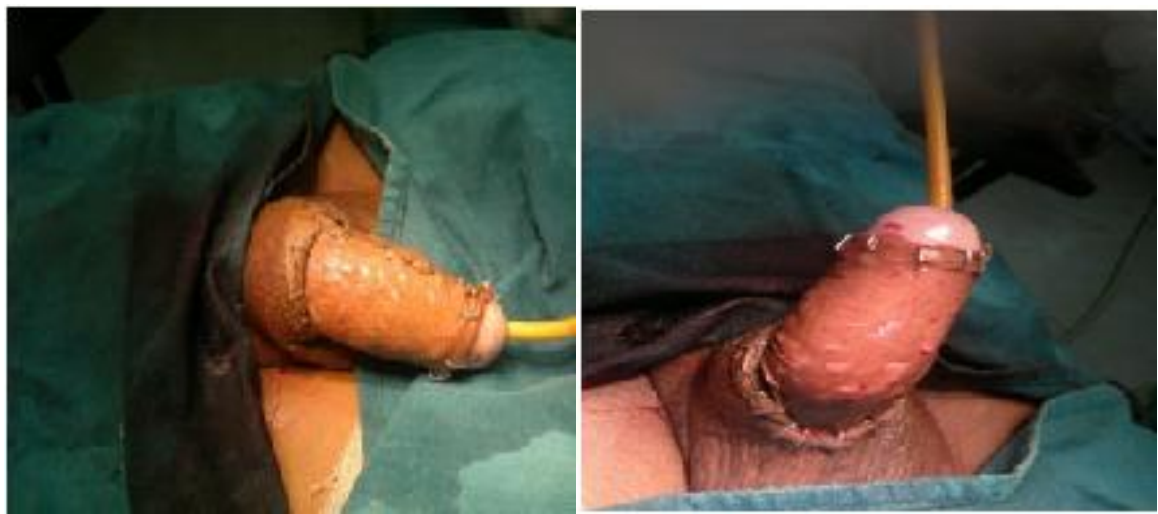

Immediate postoperative period showing stapled pins over the graft on ventral surface of penis. An occlusive dressing consisting of a mild compression bandage to ensure adequate contact of graft with recipient's bed was left in place for 7 days. The patient remained with an indwelling urinary catheter for 3 days. 


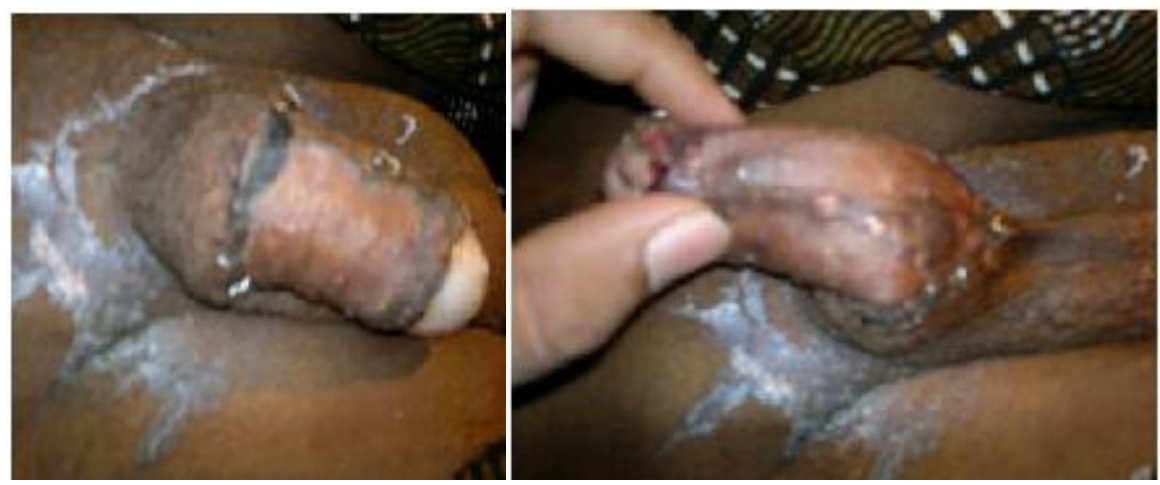

Although this surgical site is subject to contamination because of neighbouring structures, no infection, dehiscence or necrosis was observed, probably thanks to technical care and local hygiene.

DISCUSSION: Penoscrotal lymphoedema is a condition due to abnormal accumulation of lymphatic fluid subcutaneously leading to progressive enlargement of penis and scrotum, causing significant discomfort to the patient.

Although many cases of primary and secondary penoscrotal lymphoedema and/or elephantiasis has been mentioned in surgical literature and reported in surgical journals worldwide, isolated, idiopathic prepucial elephantiasis is itself an extremely rare entity.

Lymphoedema is of two types: - primary and secondary.

Primary Lymphoedema:-can be

i. Inherited (Milroy's)

ii.Praecox (Early onset)

iii. Tarda (Late onset)

Secondary Lymphoedema:-

i. Obstructive (secondary to neoplasm, radiotherapy, surgical intervention, mechanical trauma)

ii.Inflammatory (bacterial eg- Chlamydia trachomatis; parasitic eg- Wuchereria bancrofti; fungal infection)

iii. Angioneurotic

iv. Phlebitial 6

In addition to grotesque aspect, the progression of condition makes sexual intercourse impossible; impair voiding and proper hygiene of the perineal region with subsequent malodors and recurrent episode of skin infection, all causing severe damage to patient's quality of life and self esteem. ${ }^{11,12}$

Our $30 \mathrm{yr}$ old patient had prepucial swelling for 12 years, which was probably as a result of lymphatic obstruction of superficial chain of inguinoscrotal region responsible for lymphatic drainage of penile and scrotal skin. The deep chain is responsible for lymphatic drainage of testis and penile body and flows into deep inguinal and abdominal lymph node and it is usually preserved. 
Though this patient has lived in endemic region of filariasis but there was no evidence of filariasis which is difficult to explain. The etiologic factor in this patient could not be clearly identified.

Medical treatment with different approach has proven inefficient and is no longer in use. There are two methods of surgical treatment of chronic genital lymphoedema; Lymphangioplasty and Lymphangiectomy with reconstructive surgery. Lymphangioplasty is aimed at restoring lymphatic drainage with vascular anastomoses limited to cases with minor stasis, well isolated lymphatic channel, without evidence of fibrosis ${ }^{11}$. Failure in this surgical procedure and frequent recurrence has discouraged the use of this technique.

Lymphangiectomy includes removal of superficial lymphatic network which is located above the Buck's fascia and is derived from median raphe and prepucial lymphatics. The lymphatics drain into superficial posterior lymphatic channel. 6

The excision of all affected penile skin is fundamental principle for the adequate treatment of this condition and for proper resumption of function ${ }^{13}$. The major challenge is to reconstruct the penile skin and countless techniques for this procedure are part of surgical armamentarium. 7,13,14

The different surgical techniques used for lymphangiectomy and repairs of penis and scrotum include Jourdan and Meller 5, Dlepech 7,9, Larrey 9, Raghaviah 10, Vaught 9, Dandapat 8,9, Morey 10, Apesos ${ }^{7}$ and Malloy ${ }^{5}$. We opted for the split thickness skin graft.

The application of a split thickness skin graft involving the penile shaft promotes adequate skin coverage with a penile girth compatible with sexual intercourse and little alteration in sensitiveness as some patient reports.

Stapling or suturing of graft in zigzag fashion on ventral surface of the penis, a tactic which is proposed is in our opinion a key point in reconstruction, in so far as it aims at avoiding scar contracture and subsequent ventral curvature of penis.

Comparing this management technique with those described in literature 7,12 we can state that the principle of penile reconstruction were observed. As a matter of fact the coverage of penile shaft with split thickness skin graft is much better than the use of flaps, even local flaps, which notably affect tactile sensitivity and excretion ${ }^{8,9}$ and could require supplementary siygianl procedure to correct occasional sequelae.

The histopathological section showed skin tissue with papillomatosis. The dermis showed dense lymphoplasmacytic infiltration and dense fibrocartilagenous tissue with dilated lymphatic channels. These features are consistent with Elephantiasis.

Surgical complication of elephantiasis includes hemorrhage, hematoma, and urethral injury. Infection, painful erection, decreased sensitivity with scar in suture line. 7,8

CONCLUSION: Genital lymphoedema is a syndrome mostly caused by Wuchereria bancrofti or Chlamydia trachomatis and can be manifested as physical disability, social embarrassment and psychological disturbance.

The uniqueness of this case is its presentation as isolated prepucial involvement with atypical morphology, without concomitant involvement of scrotum with unclear etiology and achieving complete surgical cure without a rotational flap and vacuum assisted devices.

The patient benefitted with extensive excision of elephantoid tissue and primary penile shaft split thickness skin graft and achieved adequate functional and cosmetic outcome. 


\section{CASE REPORT}

Consent - Written informed consent was obtained from the patient for publication of this case report and accompanying images.

Competing interest- the authors declare that they have no competing interest.

Author's contribution- All authors were actively involved in the management of this patient. They also participated in the design and writing of this manuscript and all have read and approved the final version

\section{REFERENCES:}

1. K. Park (Ed) Textbook of Preventive and Social Medicine, 17th edition2012. Chapt. Lymphatic filariasis. Banabdas Bhanot, Jabalpur, India. Pg no:-199-203

2. Ollapillil J.J., Watters D.A.; Surgical Management of Elephantiasis of Male Genitalia. Br.J Urol, 1995 Aug; 76(2):213-5

3. Nutman T.B., Welier P.S. in Harrison's Internal Medicine 17th (Ed), 2008. Chapt. Filarial \& related infections, Tata McGraw Hill, New York, USA. Pg no:- 1324-1329

4. K.G. Shah, D.B. Choksi, A.S. Vohra \& J. Barad; Giant Scrotal \& Penile Elephantiasis of Idiopathic Etiology: A Case Report. The Int. Journal of Urology 2007 vol. 5 number 1

5. Mallory T.R., Wein A.J., Gross P.; Scrotal and Penile Lymphoedema:- Surgical consideration and management. J. Urology 1983, 130:263

6. Brown W.L., Woods J.E.; Lymphoedema of penis, plastic reconstruction surgery 1977; 59; 6871

7. Apesos J., Angian G.; Reconstruction of Penile \& Scrotal lymphoedema. Ann. Plastic Surgery. 1991; 27:570

8. Dandapat M.C., Mohapatro S.K., Patro S.K.; Elephantiasis of Penis \& Scrotum (A review of 350 cases) Am. J. Surgery 1985; 149:686-90

9. Prpic I.; Severe Elephantiasis of Penis \& Scrotum. Br. J. Plastic surgery. 1966; 19:178-8

10.Raghavariah N.V.; Reconstruction of Scrotal and Penile skin in elephantiasis. J. Urol. 1977; 188:128

11. Morey A.F., Mengmv, McAninch J.W.; Skin graft in reconstruction of Chronic genital lymphoedema. Urology 1997; 50: 423.57

12.Bulkely G.J.; Scrotum \& Lymphoedema. J. Urology 1962; 87: 422-429 Pubmed abstract.

13.Goldsmith H.S., Los Santos R, Biattier E.J.; Relief of Chronic Lymphoedema by omental transposition. Ann. Surgery 1967; 166:573-85

14.Sun G.S., Zhong A.G., He W, Du P, Song W.M., Ma J.G.; Reconstruction of external genitals and repair of skin defect of perineal region using three types of lateral groin flap. Ann. Plastic Surgery 1990; 24:328-34 


\section{AUTHORS:}

1. Charan Panda

2. Jamaluddin

3. Nalini Kant Mohanty

\section{PARTICULARS OF CONTRIBUTORS:}

1. Professor, Department of General Surgery, M.K.C.G. Medical College \& Hospital, Berhampur, ODISHA.

2. Junior Resident, Department of General Surgery, M.K.C.G. Medical College \& Hospital, Berhampur, ODISHA.

3. Junior Resident, Department of General Surgery, M.K.C.G. Medical College \& Hospital, Berhampur, ODISHA.

\section{NAME ADDRESS EMAIL ID OF THE} CORRESPONDING AUTHOR:

Dr. Jamaluddin, Post Graduate Student, Dept. of General Surgery, R.No. 91/P.G - 2 Hostel, M.K.C.G. M.C.H, Berhampur, Odisha.

Email- ahmadjamal225@gmail.com

Date of Submission: 03/08/2013.

Date of Peer Review: 05/08/2013.

Date of Acceptance: 16/08/2013.

Date of Publishing: 19/08/2013 